\title{
Wettability Influences Cell Behavior on Superhydrophobic Surfaces with Different Topographies
}

\author{
Bianca N. Lourenço • Giulia Marchioli • Welong Song • \\ Rui L. Reis · Clemens A. van Blitterswijk • Marcel Karperien • \\ Aart van Apeldoorn · João F. Mano
}

Received: 27 March 2012/ Accepted: 28 June 2012

(C) The Author(s) 2012. This article is published with open access at Springerlink.com

\begin{abstract}
Surface wettability and topography are recognized as critical factors influencing cell behavior on biomaterials. So far only few works have reported cell responses on surfaces exhibiting extreme wettability in combination with surface topography. The goal of this work is to study whether cell behavior on superhydrophobic surfaces is influenced by surface topography and polymer type. Biomimetic superhydrophobic rough surfaces of polystyrene and poly(L-lactic acid) with different micro/nanotopographies were obtained from smooth surfaces using a simple phase-separation based method. Total protein was quantified and showed a less adsorption of bovine serum albumin onto rough surfaces as compared to smooth surfaces of the same material. The mouse osteoblastic MC3T3-E1 cell line and primary bovine articular chondrocytes were used to study cell attachment and
\end{abstract}

B. N. Lourenço · W. Song · R. L. Reis · J. F. Mano ( $₫)$

3B's Research Group-Biomaterials, Biodegradables and

Biomimetics, Headquarters of the European Institute of

Excellence on Tissue Engineering and Regenerative Medicine,

University of Minho, AvePark, 4806-909 Taipas,

Guimarães, Portugal

e-mail: jmano@dep.uminho.pt

B. N. Lourenço · W. Song · R. L. Reis · J. F. Mano ICVS/3B's-PT Government Associate Laboratory,

Braga/Guimarães, Portugal

G. Marchioli - C. A. van Blitterswijk

Department of Tissue Regeneration, MIRA-Institute for BioMedical Technology and Technical Medicine, University of Twente, P.O. Box 217, Enschede 7500 AE, The Netherlands

G. Marchioli · M. Karperien · A. van Apeldoorn

Department of Developmental BioEngineering, MIRA-Institute for BioMedical Technology and Technical Medicine, University of Twente, P.O. Box 217, Enschede 7500 AE, The Netherlands proliferation. Cells attached and proliferate better in the smooth surfaces. The superhydrophobic surfaces allowed cells to adhere but inhibited their proliferation. This study indicates that surface wettability, rather than polymer type or the topography of the superhydrophobic surfaces, is a critical factor in determining cell behavior.

\section{Introduction}

After implantation biomaterials interact with the surrounding tissues, and ultimately cells, through their interfaces. The type of interaction is largely dependent on the surface properties of the materials, such as wettability, topography/roughness, surface charge and chemistry [1]. Understanding such phenomena is critically important to the comprehension of many fundamental questions related to cell-material interactions and for the development of biomaterials in the field of Tissue Engineering (TE) and Regenerative Medicine.

Surface properties including wettability and topography are recognized as critical factors that can directly influence cell behavior. In addition, these parameters can modify the conformation of adsorbed proteins, thereby indirectly influencing cell-substrate interactions [2-5]. Cells respond to topographical cues in many ways and the response of a wide variety of cell types have been studied on several substratum features such as grooves, ridges, steps, pores, wells and nodes in micro- and nano scales to understand the interactions between cells and different topographies [6-9].

Superhydrophobic surfaces combine micro and nanometer scale roughness along with a low surface energy material which leads to a water contact angle (WCA) higher than $150^{\circ}$ [10]. Many examples of superhydrophobic surfaces can be found in Nature, such as the lotus leave, 
which have been used as inspiration for the production of synthetic superhydrophobic surfaces using a large number of techniques [11, 12]. Superhydrophobic surfaces have been developed for several applications including antifouling, non wettable textiles, transparent and antireflective self-cleaning coatings or humidity-proof coatings for electronic devices [13, 14]. We have shown that such surfaces could be useful in several biomedical-related areas. They could be used as substrates for particle production [15-18], open microfluidic devices [19] and the production of arrays for high-throughput analysis [20]. Anti-bioadhesion applications, aimed at preventing protein adsorption and cell adhesion have been mostly studied in blood compatible materials [21, 22]. Nonetheless, few works are found in literature reporting the use of superhydrophobic surfaces as support for cell response studies [23-28].

Superhydrophobic surfaces may display different topographies, but to our knowledge the influence of such different textures on cell behavior have never been reported. Cell behavior is dependent not only on surface properties but may be also affected by the cell type [23, 29]. There is both fundamental and practical interest in combining different topographies with surfaces with extreme wettability properties in order to investigate if the influence of topography or cell type is as important as the influence of wettability itself on cell behavior.

In this work, biomimetic superhydrophobic surfaces with distinct topographies were obtained from two smooth polymeric surfaces, polystyrene (PS) and poly(L-lactic acid) (PLLA), by a simple and low-cost phase separation method. Our aim was to investigate the influence of surface topography and the chemical nature of superhydrophobic surfaces on the cellular response using two distinct cell types: a cell line and a primary cell culture. PS is a well known amorphous aromatic polymer, and is frequently used as control cell-material interaction studies. PLLA is a biodegradable, semi-crystalline polyester proposed to be used in several biomedical applications [30-32]. The different thermal behavior of these two materials allows to generate different surface textures when substrates are processed by a phase separation methodology. This parameter is used in this work to produce superhydrophobic surfaces with distinct topographies on both polymer types.

\section{Materials and Methods}

\subsection{Materials}

Smooth PS films used in this work were purchased from GoodFellow Cambridge Limited, England, with a thickness of $0.25 \mathrm{~mm}$.
A high stereoregular PLLA with a Mn of 69.000 and a Mw/Mn of 1.734 was obtained from Cargill Dow LLC, USA. The glass transition temperature and melting temperature of this polymer were 60 and $162{ }^{\circ} \mathrm{C}$, respectively [33].

Tetrahydrofuran (THF) and sterile agarose were purchased from Sigma-Aldrich. 1,4-Dioxane (p.a. $\geq 99.5 \%$ ) and absolute ethanol were obtained by Fluka and Panreac, respectively.

\subsection{Superhydrophobic Surface Production}

\subsubsection{Preparation of PS Superhydrophobic Surfaces}

PS substrates were obtained cutting the smooth PS films into small squares of $5 \times 5 \mathrm{~cm}^{2}$ and were cleaned by immersion in $70 \%$ ethanol $(\mathrm{v} / \mathrm{v})$ in an ultrasonic bath for $10 \mathrm{~min}$.

A $70 \mathrm{mg} / \mathrm{mL}$ solution of PS (injection molding grade) in THF was prepared and then mixed with absolute ethanol in a ratio of 2: $1.3(\mathrm{v} / \mathrm{v})$. The mixture was uniformly dispensed onto PS substrates, resulting in the formation of an opaque or semi-transparent layer. After $10 \mathrm{~s}$ on air, the substrates were then immersed in absolute ethanol for $1 \mathrm{~min}$. Afterwards the surfaces were dried at room temperature, resulting in rough superhydrophobic surfaces of PS.

\subsubsection{Preparation of PLLA Superhydrophobic Surfaces}

Flat smooth PLLA substrates were produced by melting PLLA powder between two glass slides subjected to compression at $200{ }^{\circ} \mathrm{C}$ followed by cooling in water [25].

A $13 \%(\mathrm{wt} / \mathrm{v})$ PLLA solution in 1, 4-dioxane was casted on the substrates. After an evaporation period of a few seconds the substrates were immersed in absolute ethanol to induce the phase separation of the casted solution. The samples were first dried under nitrogen flow and then in the vacuum oven at $30{ }^{\circ} \mathrm{C}$ for $24 \mathrm{~h}$ to eliminate all solvent residues. When the samples were completely dry, the upper part was removed giving rise to rough superhydrophobic surfaces of PLLA.

All PS and PLLA surfaces were punched into circular samples with a diameter of $8 \mathrm{~mm}$ and their nomenclatures were the following: PS-S and PLLA-S for the smooth PS and PLLA substrates, respectively, and PS-R and PLLA-R for the corresponding rough surfaces.

\subsection{Characterization}

\subsubsection{Scanning Electron Microscopy}

Surface topography was analyzed, before and after processing, using the phase-inversion method, by a Leica Cambridge S-360 scanning electron microscope (Leica Cambridge, UK). All samples were pre-coated with a 
conductive layer of sputtered gold. The analyses were performed at an accelerating voltage of $15 \mathrm{kV}$ at different magnifications.

\subsubsection{Optical Profilometry}

The surface average roughness and the root mean square roughness of the PS and PLLA rough surfaces were measured with a Wyko-NT1100 optical profiler. The measurements were carried out applying the vertical scanning interferometry (VSI) mode.

\subsubsection{Contact Angle Measurement}

The wettability of different surfaces was characterized by contact angle (CA) measurements. Static CA measurements were performed using the sessile drop method on an OCA15+ goniometer (DataPhysics, Germany) under ambient conditions at room temperature. Milli-Q water $(6 \mu \mathrm{L})$ was dropped on the surfaces and pictures were taken after water drop stabilization. Three samples of each surface type were measured five times. The CA measurements of all samples were performed in the same week of their preparation and 12 weeks later.

\subsubsection{X-Ray Photoelectron Spectroscopy}

The surface chemical composition of smooth and rough surfaces was investigated by X-Ray Photoelectron Spectroscopy (XPS), using a Physical Electronics Quantera SXM (scanning XPS microprobe) system with monochromatic $\mathrm{Al} \mathrm{K} \alpha$ radiation $(h=1486.6 \mathrm{eV} / 15 \mathrm{kV})$ shot at an angle of $45^{\circ}$ toward the surfaces. Survey spectra were obtained with pass energy of $224 \mathrm{eV}$ and a step size of $0.8 \mathrm{eV}$. The software used was a Compass for XPS control, Multipak v.8.0 for data reduction. The measurements were carried out in triplicate 12 weeks after samples' preparation.

\subsection{Adsorbed Protein Quantification}

\subsubsection{BCA Assay}

Protein adsorption on samples was analyzed by colorimetric detection and quantification of total protein using a bicinchoninic acid (BCA) protein assay kit (Pierce Chemical Co, USA). This system utilizes BCA as the detection reagent for $\mathrm{Cu}^{+1}$, which is formed when $\mathrm{Cu}^{+2}$ is reduced by protein in an alkaline environment. The purple colored reaction product exhibits a strong absorbance at $562 \mathrm{~nm}$ that is linear with increasing protein concentration.

Surfaces were fixed on the bottom of an ultra low attachment plate and immersed in $500 \mu \mathrm{g} / \mathrm{mL}$ of bovine serum albumin (BSA, Sigma-Aldrich) in phosphate buffered saline (PBS, Gibco). The same plate was used as control. After $24 \mathrm{~h}$ of incubation in a humidified atmosphere with $5 \% \mathrm{CO}_{2}$ at $37{ }^{\circ} \mathrm{C}$, the remaining protein in solution was assayed for total protein quantification. The assay was performed according to manufacturer's instructions. Accordingly, protein concentrations were determined with reference to standards of BSA by comparison to a known standard curve. The absorbance was read on a microplate spectrophotometer (Tecan) at $562 \mathrm{~nm}$ and the total protein adsorbed on the sample was calculated subtracting the sample value from the value obtained in the control (empty well).

\subsection{Cells Culture}

\subsubsection{Mouse Osteoblastic Cell Line Culture}

The murine osteoblastic cell line MC3T3-E1 were suspended in alpha Minimum Essential Medium Eagle $(\alpha$-MEM, Invitrogen) supplemented with $10 \%$ of heatinactivated fetal bovine serum (FBS, Sigma-Aldrich), $2 \mathrm{mM} \alpha$-glutamine (Invitrogen), $100 \mathrm{U} / 100 \mu \mathrm{g} / \mathrm{mL}$ penicillin/streptomycin (Pens/Strep, Invitrogen) and $1 \mathrm{mM}$ sodium pyruvate (Invitrogen). Adherent MC3T3-E1 cells were expanded in tissue culture flasks and incubated in a humidified atmosphere with $5 \% \mathrm{CO}_{2}$ at $37{ }^{\circ} \mathrm{C}$. The medium was changed every third day until the cells reached $80 \%$ of confluence.

\subsubsection{Bovine Articular Chondrocyte Culture}

Bovine articular chondrocytes $(\mathrm{BCH})$ were isolated from harvested bovine cartilage from the patellar-femoral groove of calf legs through enzymatic digestion. Cartilage tissue was cut in small pieces and chondrocytes were isolated by incubation in Dulbecco's modified Eagle's medium (DMEM, Invitrogen) containing $0.2 \%$ collagenase type II overnight at $37{ }^{\circ} \mathrm{C}$. The isolated chondrocytes were washed in PBS, centrifuged and re-suspended in chondrocyte proliferation medium containing DMEM high glucose (Invitrogen) with $10 \%$ FBS (Sigma-Aldrich), $0.1 \mathrm{mM}$ non-essential amino acids (Sigma-Aldrich), 100U/100 $\mu \mathrm{g} / \mathrm{mL}$ Pen/Strep (Invitrogen), $0.4 \mathrm{mM}$ proline (Sigma-Aldrich) and $0.2 \mathrm{mM}$ Ascorbic-acid-2-Phosphate (Invitrogen), culture expanded in tissue culture flasks and incubated in a humidified atmosphere with $5 \% \mathrm{CO}_{2}$ at $37{ }^{\circ} \mathrm{C}$. The medium was changed every third day until the cells reached $80 \%$ of confluence.

Prior to cell seeding, the surfaces were sterilized by immersion in $70 \%(\mathrm{v} / \mathrm{v})$ of ethanol for $2 \mathrm{~h}$, rinsed three times with PBS and then fixed to the bottom of 48-well plates with a gelseal (GE Healthcare Bio-Science Corp.). 
Each well containing the samples was filled with a heated agarose solution (agarose/PBS) $3 \%(\mathrm{wt} / \mathrm{v})$. The plates were left $1 \mathrm{~h}$ in the fridge at $4{ }^{\circ} \mathrm{C}$ to solidify and create an agarose mould. Tissue culture polystyrene (TCPS) wells were used as control and agarose moulds were also made inside of these wells. After solidification the agarose moulds were punched with the same size of the samples and the remaining holes were filled with culture medium for overnight pre-incubation prior to cells seeding.

The agarose moulds were used in this work in order to force cell adherence to the sample and not to the TCPS. Moreover, agarose moulds ensured that cell attachment was not impaired due to culture medium repellence from superhydrophobic samples and sample floating.

At confluence cells were detached using $0.25 \%$ trypsin/ EDTA solution (Sigma-Aldrich). Cells were re-suspended in medium and seeded on each experimental group as well as in TCPS (controls) with $1 \times 10^{4}$ cells in $300 \mu \mathrm{L}$ of medium. The medium was changed every 2 days and before each assay the agarose moulds were carefully removed.

\subsection{Cell Viability, Adhesion and Proliferation Studies}

Cell viability and metabolic activity of MC3T3-E1 and BCH were studied using a MTT [3-(4, 5-dimethyl-2thiazolyl)-2, 5-dimethyl tetrazolium bromide] and live/ dead assays. The MTT assay was performed at day 1 and live/dead assay at days 1 and 7 , according to manufacturer's specifications.

Cell adhesion on smooth and rough surfaces was studied by a DNA quantification assay carried out after 3 days of culture using both cell types. In order to study the influence of these surfaces on cell proliferation, the Alamar Blue assay was performed with MC3T3-E1 cell line at 1, 3 and 7 days.

The surfaces were further observed by Scanning Electron Microscopy (SEM) to investigate MC3T3-E1 cell line and $\mathrm{BCH}$ morphology at days 1, 3 and 7.

\subsubsection{MTT Quantification}

MTT assay measures the metabolic activity of viable cells, when the tetrazolium ring of MTT is converted by a mitochondrial dehydrogenase to a water insoluble purple formazan salt. In brief, the culture medium of each cell culture was removed from the wells and rinsed twice with $400 \mu \mathrm{L}$ of PBS. Then, $400 \mu \mathrm{L}$ of complete culture medium and $40 \mu \mathrm{L}$ of MTT solution $(5 \mathrm{mg} / \mathrm{mL})$ were added to each well. The plate was incubated at $37{ }^{\circ} \mathrm{C}$ in humidified atmosphere with $5 \% \mathrm{CO}_{2}$ for $4 \mathrm{~h}$. Subsequently, the supernatant was carefully discarded and the remaining MTT-formazan crystals dissolved by adding $400 \mu \mathrm{L}$ of dimethyl sulfoxide (DMSO). The plate was left under stirring for $5 \mathrm{~min}$ in an orbital shaker $(200 \mathrm{rpm})$. The content of each well was transferred to a microtube and centrifuged at 1,300 rpm for $2 \mathrm{~min}$. $200 \mu \mathrm{L}$ aliquots of the supernatant were transferred into a 96-well plate and a control with $200 \mu \mathrm{L}$ of DMSO was also prepared. The absorbance was read on a microplate spectrophotometer (Tecan) at $540 \mathrm{~nm}$ with background subtraction at $690 \mathrm{~nm}$. The results were expressed in percentage relative to the cells seeded on TCPS.

\subsubsection{Live/Dead Assay}

Live/dead assay (Invitrogen) was performed according to the protocol. The samples were washed with PBS and stained with calcein-AM $(2 \mu \mathrm{M})$ and ethidium homodimer-1 $(4 \mu \mathrm{M})$ in PBS and incubated for $30 \mathrm{~min}$ in dark at $37{ }^{\circ} \mathrm{C}$ in a $5 \%$ $\mathrm{CO}_{2}$ humidified atmosphere. The samples were immediately examined in a fluorescent microscope (Nikon Eclipse E600) using a fluorescein isothiocyanate (FITC) for green live cells, and Texas Red filters for dead cells, stained red.

\subsubsection{DNA Quantification Assay}

Quantification of total DNA was performed with Quant-iT PicoGreen dsDNA assay kit (Molecular Probes/Invitrogen, USA).

After 3 days of culture, samples were transferred into eppendorf tubes and sonicated (for $5 \mathrm{~s}$ for 4 times) in $200 \mu \mathrm{L}$ of distillated water. The samples were then vortexed and $10 \mu \mathrm{L}$ of each plus $90 \mu \mathrm{L}$ of PicoGreen solution were added to an opaque white 96-well plate. After 5 min of incubation in dark the plate was read using a microplate reader $\left(\right.$ Victor $^{3}$, Perkin-Elmer, USA) at an excitation wavelength of $485 \mathrm{~nm}$ and an emission wavelength of $520 \mathrm{~nm}$.

\subsubsection{Alamar Blue Assay}

Alamar Blue reduction was investigated as a measure of cell metabolic activity (Biosource, DAL 1100). Briefly, cell culture medium was replaced with $10 \%(\mathrm{v} / \mathrm{v})$ of Alamar Blue solution in each well. After $4 \mathrm{~h}$ of incubation in a humidified atmosphere with $5 \% \mathrm{CO}_{2}$ at $37{ }^{\circ} \mathrm{C}$, the fluorescence of samples $(200 \mu \mathrm{L})$ was measured using a microplate reader (Victor $^{3}$, Perkin Elmer, USA) at an excitation wavelength of $545 \mathrm{~nm}$ and an emission wavelength of $590 \mathrm{~nm}$.

\subsubsection{Scanning Electron Microscopy Observation}

MC3T3-E1 and BCH cells morphology was evaluated by SEM, after the samples being fixed with $10 \%(\mathrm{v} / \mathrm{v})$ formalin for $30 \mathrm{~min}$, dehydrated using graded ethanol solutions (70, 8090 and $100 \%(\mathrm{v} / \mathrm{v}), 30 \mathrm{~min}$ in each) and critical point dried (Balzers CPD 030). All samples were 
coated with gold using a sputter coater (Cressington) for $60 \mathrm{~s}$ at a current of $40 \mathrm{~mA}$. The analysis was performed on a Philips XL 30 ESEM-FEG microscope at an accelerating voltage of $10 \mathrm{kV}$.

\subsection{Statistical Analysis}

Each experiment was carried out in triplicate unless otherwise specified. All the results on this study are reported as mean \pm standard deviation (SD). Experimental data were analyzed using the one-way ANOVA test to assess statistical significance of the results, except WCA changes that were analyzed by Student's $t$ test. Statistical significance was set at a $p$ value of $<0.05(*$ and \#) or $<0.01(* *)$.

\section{Results and Discussion}

\subsection{Physical-Chemical Characterization of Surfaces}

SEM micrographs depicting the morphology of the PS and PLLA rough surfaces are shown in Fig. 1. The surfaces exhibit a hierarchical micro and nano-structured roughness, which was induced when the polymers were dissolved in their respective solvents mixed with the non-solvent (ethanol) forcing precipitation. The mass transfer of the non-solvent and solvent across the interface forces the homogeneous solution to become thermodynamically unstable resulting in phase separation. PS and PLLA form both a poor and rich polymer phase. In the poor phase, polymer nuclei are formed by precipitation. In order to decrease surface energy (tension) the rich polymer phase aggregates around these nuclei. Subsequently, polymer precipitation within the rich PS and PLLA phase, causes a continuous deposition of spheres on the surface which decreases the surface tension even more [34].

Despite similar methods to prepare PS and PLLA rough surfaces, the surfaces have different topographies caused by the different physical properties of the polymers: PS is an amorphous and PLLA is a semi-crystalline polymer. The rough structure at the micro-level of PS-R and PLLA-R surfaces was further characterized using optical profilometry (Fig. 2). PS-R exhibits randomly distributed spheres with sizes from 50 to $200 \mathrm{~nm}$ that are agglomerated in larger micrometer structures (Fig. 1b and c for higher magnification) with an average roughness of $13.41 \pm 2.83 \mu \mathrm{m}$ (Fig. 2a), while PLLA-R shows well defined individual papilla-like structures with an average particle diameter of $10 \mu \mathrm{m}$ exhibiting clear rough texture at the nanometer level (Fig. 1e and $\mathrm{f}$ for higher magnification), similar to the papillae nanostructures of the lotus leaf [35]. PLLA-R also presents a textured surface at the micrometer scale with an average roughness of $8.28 \pm 0.66 \mu \mathrm{m}$ (Fig. 2b).

The wetting behavior and surface chemistry of smooth and rough surfaces were investigated by water contact angle (WCA) measurements and XPS, respectively. The phase separation method transforms the hydrophobic smooth surfaces into rough superhydrophobic surfaces $\left(\right.$ WCA $>150^{\circ}$ ), which wettability remained stable over time (Fig. 3).

The high-resolution C1s spectra of the PS and PLLA samples are shown in Fig. 4 and revealed three peaks, which were decomposed into Gaussian peaks using a nonlinear fitting algorithm. For PS-S and PS-R surfaces, the high-resolution spectrum consists of a hydrocarbon

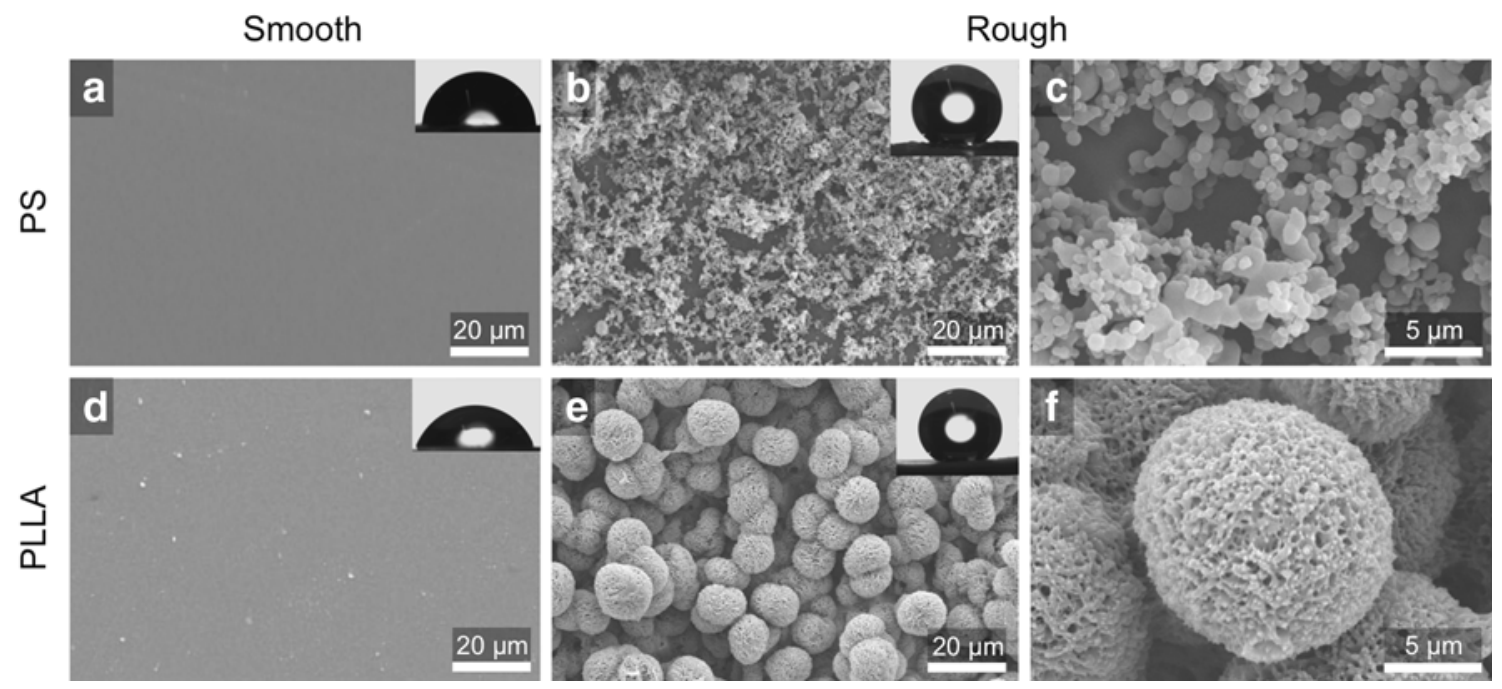

Fig. 1 SEM microphotographs of PS (a, b, c) and PLLA (d, e, f) surfaces before (a, d) and after (b, $\mathbf{c}, \mathbf{e}, \mathbf{f})$ phase inversion based methodology. $\mathbf{c}$ and $\mathbf{f}$ Represent magnifications of $\mathbf{b}$ and $\mathbf{e}$ respectively. The insets show photographs of a water droplet deposited on the corresponding surfaces 


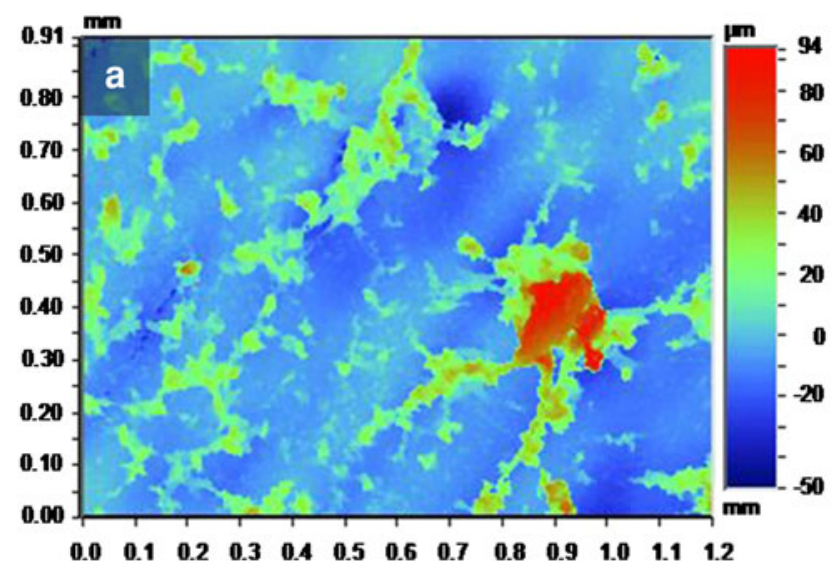

Fig. 2 Optical profilometry of representative PS-R (a) and PLLA-R (b) samples with an area of $1.2 \times 0.9 \mathrm{~mm}^{2}$ performed applying the VSI mode. a PS-R surface with an average roughness of $13.41 \pm 2.83 \mu \mathrm{m}$

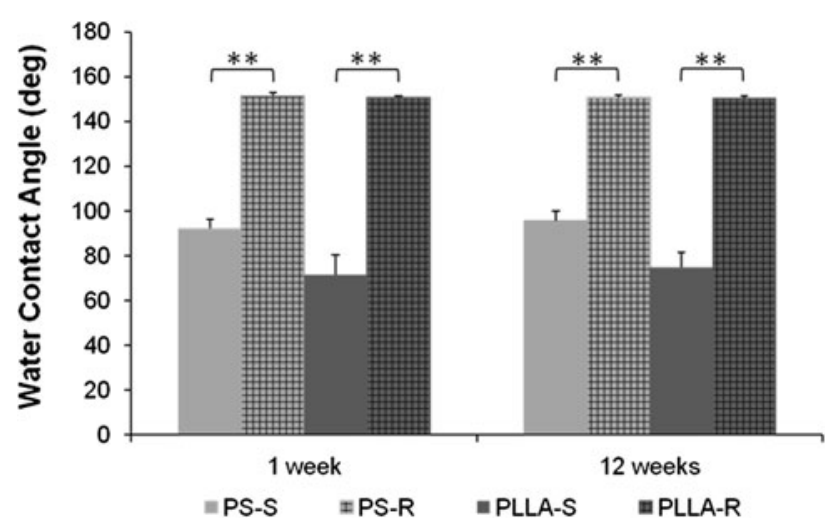

Fig. 3 Water contact angle measurements on the different surfaces at week 1 and week 12 using the sessile drop method. Data represent the mean of five experiments \pm SD. Significant differences were found for $p<0.01(* *)$ compared to the respective smooth surface

peak at $285.0 \mathrm{eV}$, an aromatic carbon peak at $284.7 \mathrm{eV}$ and a broad aromatic peak at about $291.5 \mathrm{eV}$. In the case of PLLA-S and PLLA-R surfaces, the C1s $285.0 \mathrm{eV}$ peak was assigned to the main backbone carbon peak, $287.3 \mathrm{eV}$ to $\mathrm{C}-\mathrm{O}$ group and $289.5 \mathrm{eV}$ to $\mathrm{O}=\mathrm{C}-\mathrm{O}$ group. As expected, O1s spectra did not show any significant differences between PS-S and PS-R and between PLLA-S and PLLA-R. These results are consistent with the molecular structure of PS and PLLA, respectively.

XPS analysis suggested that the chemistry of rough and smooth surfaces were similar for each polymer, which means that the chemistry is maintained on the rough surfaces that only differ from their original smooth surfaces by topographic features [19]. The superhydrophobicity is a direct consequence of the change in surface roughness, consisting of a combination of micro and nanometer scale roughness combined with a low surface energy material [36].

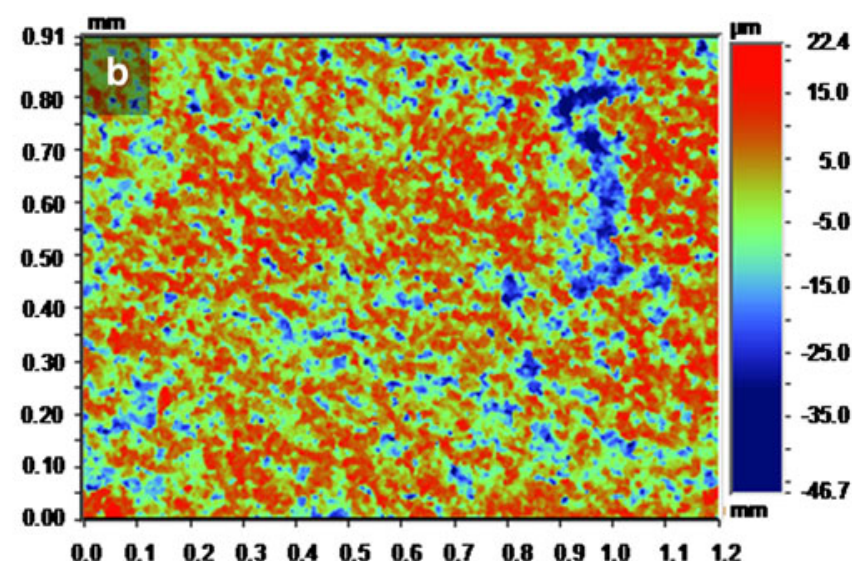

and a root mean square roughness of $20.65 \pm 5.13 \mu \mathrm{m}$. b PLLA-R surface with an average roughness of $8.28 \pm 0.66 \mu \mathrm{m}$ and a root mean square roughness of $10.76 \pm 0.84 \mu \mathrm{m}$

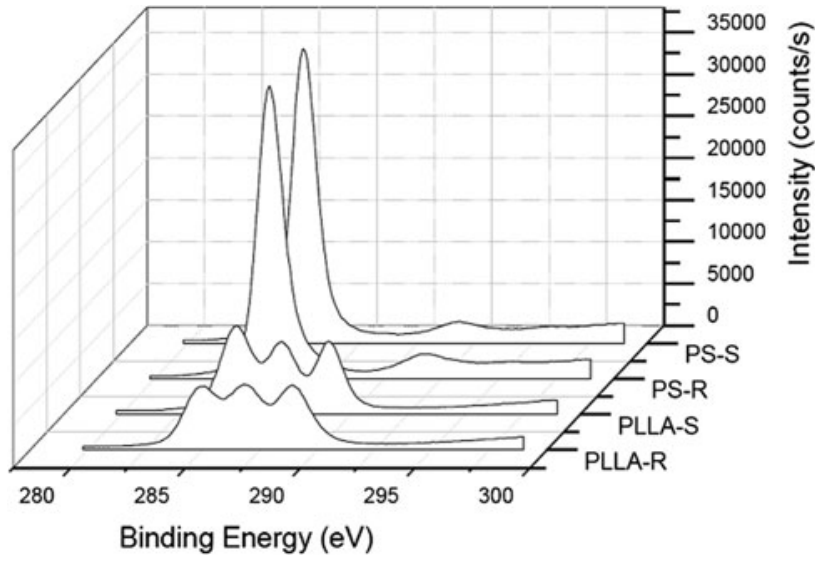

Fig. 4 X-ray photoelectron spectroscopy high resolution C1s spectrum of smooth and rough surfaces of PS (PS-S, PS-R) and PLLA (PLLA-S, PLLA-R). A representative measurement is shown

\subsection{Protein Adsorption on Surfaces}

It is widely accepted that cellular responses to biomaterial are not only mediated by direct contact, but also through an interfacial layer created on material surface once it is in contact with a physiological environment. This interfacial layer is a result of competitive adsorption of proteins from the milieu onto the material surface [37]. The composition of this protein layer and the conformation and orientation of the proteins within, can affect cellular responses such as for example cell adhesion [38].

In order to gain insight into the above mentioned process the adsorption of a model protein, bovine serum albumin (BSA), was analyzed. We performed a BCA assay in order to investigate the effect of surface topography on protein adsorption between topographic cues comparable to what was described elsewhere [39-41]. So far just a few studies 


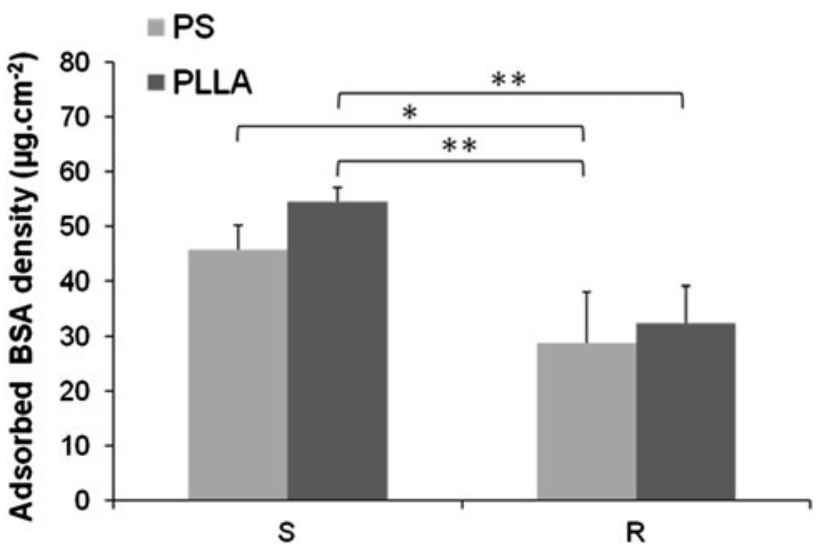

Fig. 5 BCA assay showing albumin adsorption on PS and PLLA surfaces after $24 \mathrm{~h}$ of immersion in $500 \mu \mathrm{g} / \mathrm{mL}$ of BSA. Data are reported as mean $\pm \mathrm{SD}(n=3)$ and significant differences were found for $(*) p<0.05$ and $(* *) p<0.01$

reported protein adsorption on surfaces exhibiting extreme contact angles [20, 42, 43]. A comparison of quantitative outcome of these BSA adsorption studies onto smooth and rough surfaces after $24 \mathrm{~h}$ is shown in Fig. 5.

As expected, protein adsorption on superhydrophobic surfaces tended to be reduced when compared to more wettable surfaces. No statistical differences were found between the protein adsorbed between PS-S and PLLA-S, nor between PS-R and PLLA-R substrates. In contrast, the amount of protein adsorbed onto rough surfaces was significantly lower when compared with smooth surfaces. This fact indicates the influence of wettability on protein adsorption and this effect appears independent from the kind of topography of the rough surfaces. Our findings are in agreement with previous works $[20,42,44]$ and may be explained by a model proposed by Cassie and Baxter [45]. This model postulates that an increase in surface roughness at the micro and nanometer scale leads to superhydrophobicity as a consequence of the fact that liquid can not intrude into the lower regions of the topographic features and a fraction of the surface of the drop in contact with the substrate is suspended by enclosed air pockets.

According to the Cassie-Baxter model a dissolved protein is in direct contact just with a fraction of the material's surface. Such regions will be able to adsorb the proteins from the protein solution, explaining why high contact angles of PS-R and PLLA-R were not sufficient to completely prevent protein adsorption.

\subsection{Cell Viability, Adhesion and Proliferation}

The biological response of superhydrophobic rough surfaces has led to contradictory results when compared to smooth surfaces. Some authors reported higher cell affinity to rough surfaces [23, 46-49] and others the opposite [25, $26,42,48]$. In general, only a few cells can adhere on superhydrophobic surfaces, therefore decreasing their proliferative capacity [26, 42]. In contrast, some studies have shown cell proliferation and survival $[46,48]$ and in some cases even differentiation [47] and enhanced transfection efficiency [49]. But one also has to keep in mind that cell behavior can be cell type dependent [23, 29].

Attachment, adhesion and spreading are the first phases of cell-material interactions and the quality of these stages influences the capacity of cells to proliferate on contact with the material [50]. In order to investigate the biological performance of PS and PLLA surfaces and evaluate the influence of surface wettability, topography and chemistry MC3T3-E1 cells and primary BCH were used as a model for in vitro evaluation. Both cell types were seeded on the different surfaces and viability, attachment and proliferation were investigated.

Cell viability/cytotoxicity was assessed using both a MTT assay (Fig. 6) and a live-dead assay (Fig. 7). In all the conditions tested, the viability of $\mathrm{BCH}$ cells tended to be lower than MC3T3-E1 cells. Cell viability at the rough
Fig. 6 MTT quantification of MC3T3-E1 cell line and bovine articular chondrocytes $(\mathrm{BCH})$ on the different surfaces and on tissue culture polystyrene (TCPS) as control after 1 day in culture. Data are expressed as mean $\%$ change compared to control $\pm \operatorname{SD}(n=3)$.

Significant differences between different surface types on the same culture day were found for (*) $p<0.05$ and $(* *) p<0.01$

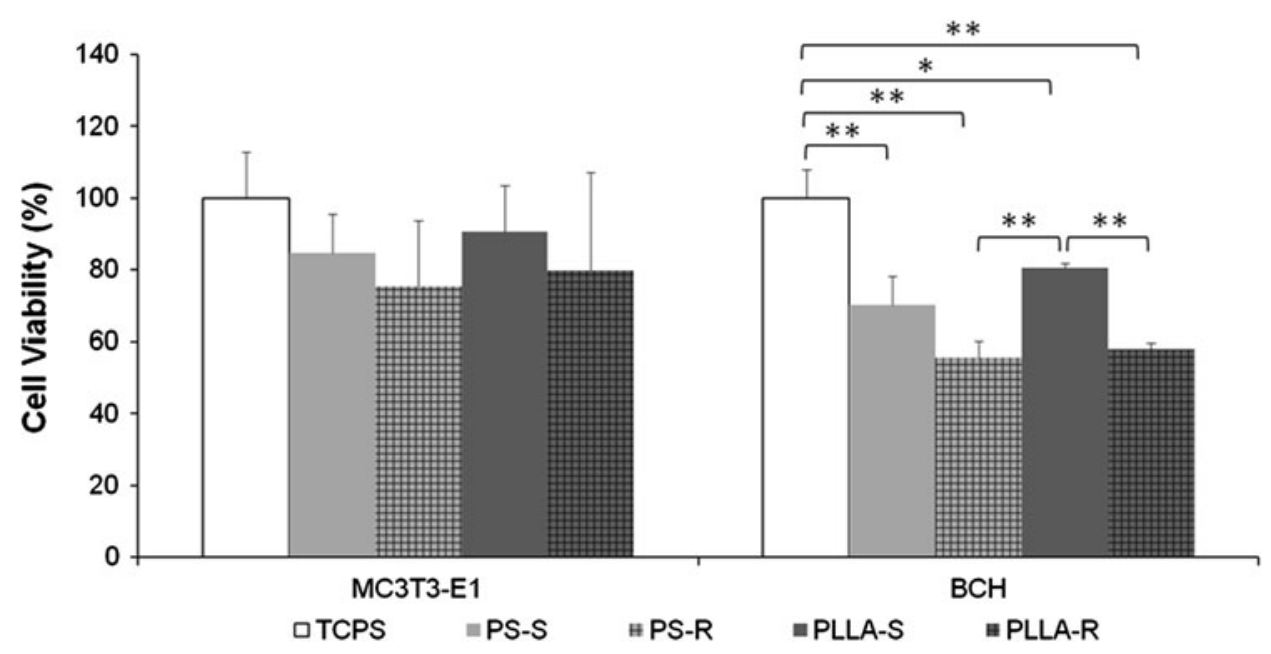


MC3T3-E1
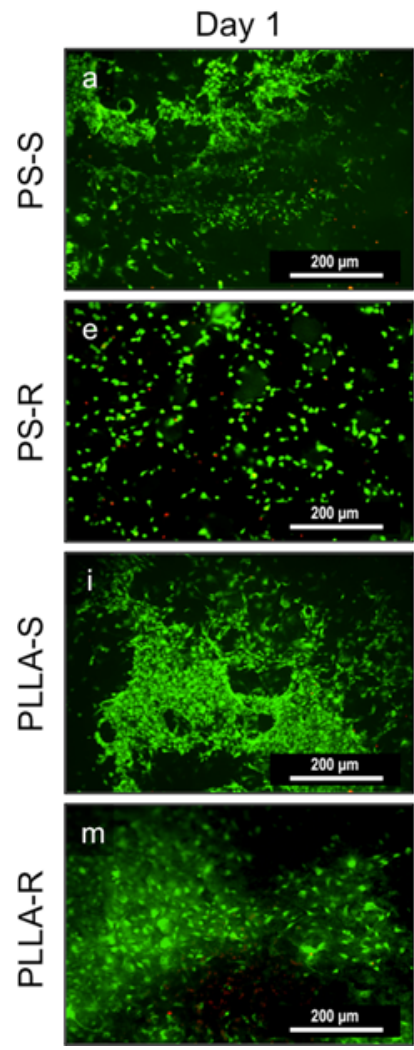

Fig. 7 Live-dead assay showing MC3T3-E1 cell line and bovine articular chondrocytes $(\mathrm{BCH})$ at the PS surfaces $(\mathbf{e}-\mathbf{h})$ and at the PLLA surfaces (i-p) at day 1 and 7 of culture. Cells were stained with calcein-AM/ethidium homodimer (dead cells stain red and living cells

surfaces was generally lower than at the corresponding smooth surfaces, especially for $\mathrm{BCH}$. As seen before for the case of the protein adsorption, cell viability seems to be not dependent on the chemical nature of the two polymers and also not sensitive to the topography of the superhydrophobic surfaces.

As shown in Fig. 7, live-dead assay displayed distinct surface biocompatibility, cell attachment and cell proliferation. In general more live cells (green) were seen on smooth surfaces as compared to the rough counterpart after 1 day of culture, being consistent with the MTT and DNA quantification (Fig. 8). After 7 days in culture, cells started to be confluent on smooth surfaces, but the same did not happen on rough surfaces, most likely because the number of cells on the rough surfaces was lower given by the reduced cell viability found after 1 day of culture. These experiments showed that both cell types preferred to adhere to and proliferate on smooth surfaces rather than on textured surfaces.

DNA quantification confirmed that more cells were observed on the smooth surfaces (Fig. 8). MC3T3-E1 cells showed better cell attachment than bovine articular
$\mathrm{BCH}$
Day 1

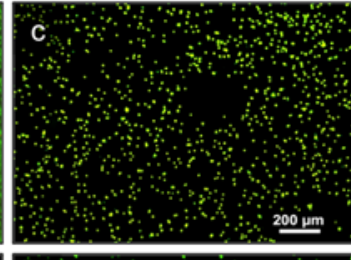

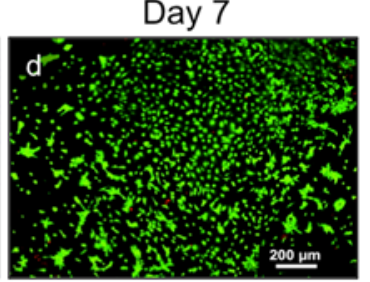
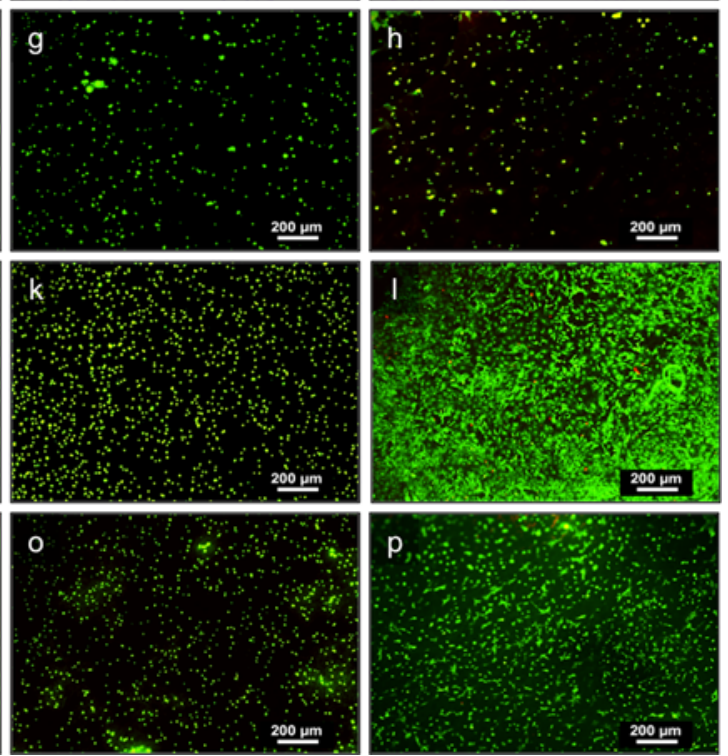

green) and visualized using fluorescence microscopy. A representative picture is shown for each condition. Cell density: $1 \times 10^{4}$ cells/ $300 \mu \mathrm{L}$

chondrocytes. Our results indicated that polymer composition and surface topography did not influence cell attachment on superhydrophobic surfaces, suggesting that extreme wettability might be the determining factor explaining these observations.

In order to evaluate the effect of surface roughness on cell proliferation, an Alamar Blue assay was performed using MC3T3-E1 cells cultured for 7 days on treated and non treated surfaces-see Fig. 9.

At day 1, rough surfaces presented lower fluorescence as compared to smooth surfaces. From day 1 to day 3, cell proliferation increased for the smooth surfaces while small differences were observed for the rough surfaces. The values of day 3 are in line with the DNA quantification results (Fig. 8). From day 3 to day 7, cell proliferation increased significantly only on the smooth surfaces, but no proliferation of cells could be seen on the rough surfaces. At day 7, strong differences were observed between smooth and rough surfaces that contrasted with the small differences found between the polymers. In addition: (i) Cell proliferation significantly increased with prolonged culture time on PS-S and PLLA-S that exhibited similar 
Fig. 8 DNA quantification of MC3T3-E1 cell line and bovine articular chondrocytes $(\mathrm{BCH})$ on the produced surfaces and the control after 3 days of culture. Significant differences between different surface types on the same culture day were found for $\left(^{*}\right) p<0.05$ and $(* *) p<0.01$. Data are expressed as mean \pm SD $(n=3)$
Fig. 9 Alamar Blue assay of MC3T3-E1 cell line on the produced surfaces and the control, after 1, 3 and 7 days of culture. Significant differences between different surface types on the same culture day were found for $\left(^{*}\right) p<0.05$ and (**) $p<0.01$. Hash represents significant differences between the same surface type on different culture days $(p<0.05)$. Data are expressed as mean $\pm \mathrm{SD}(n=3)$

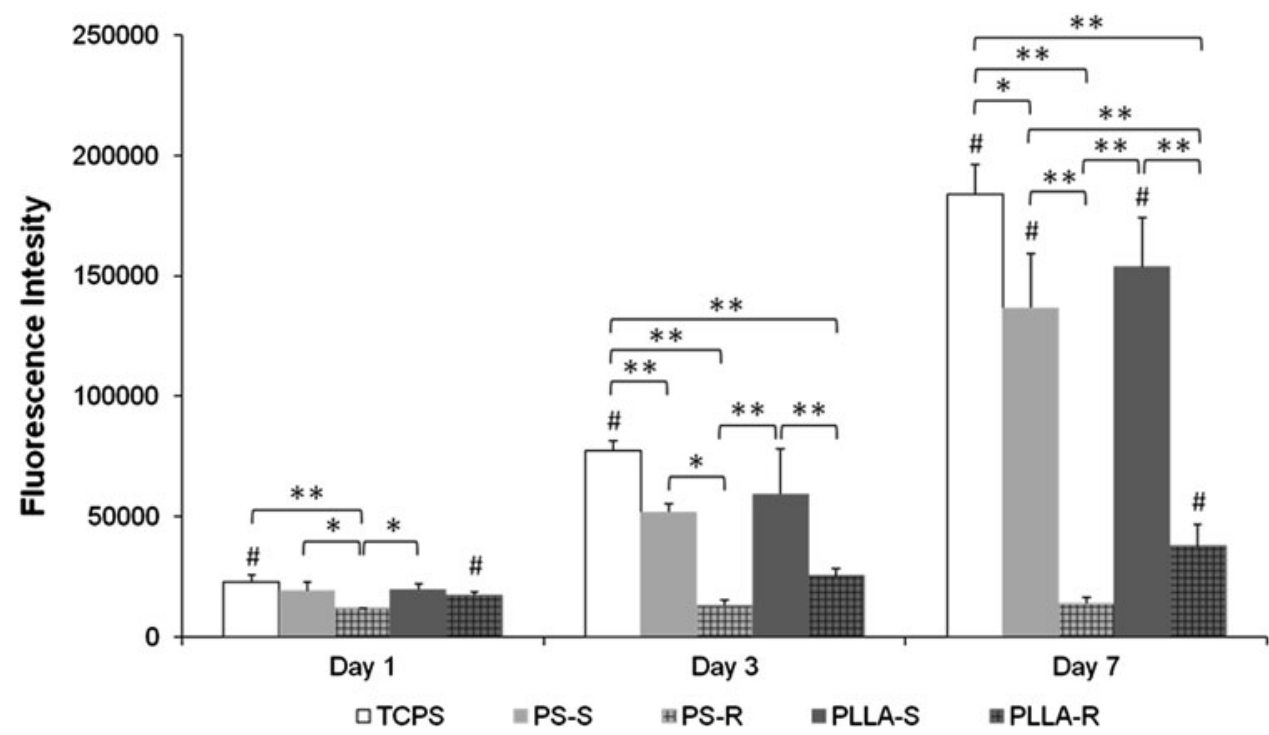

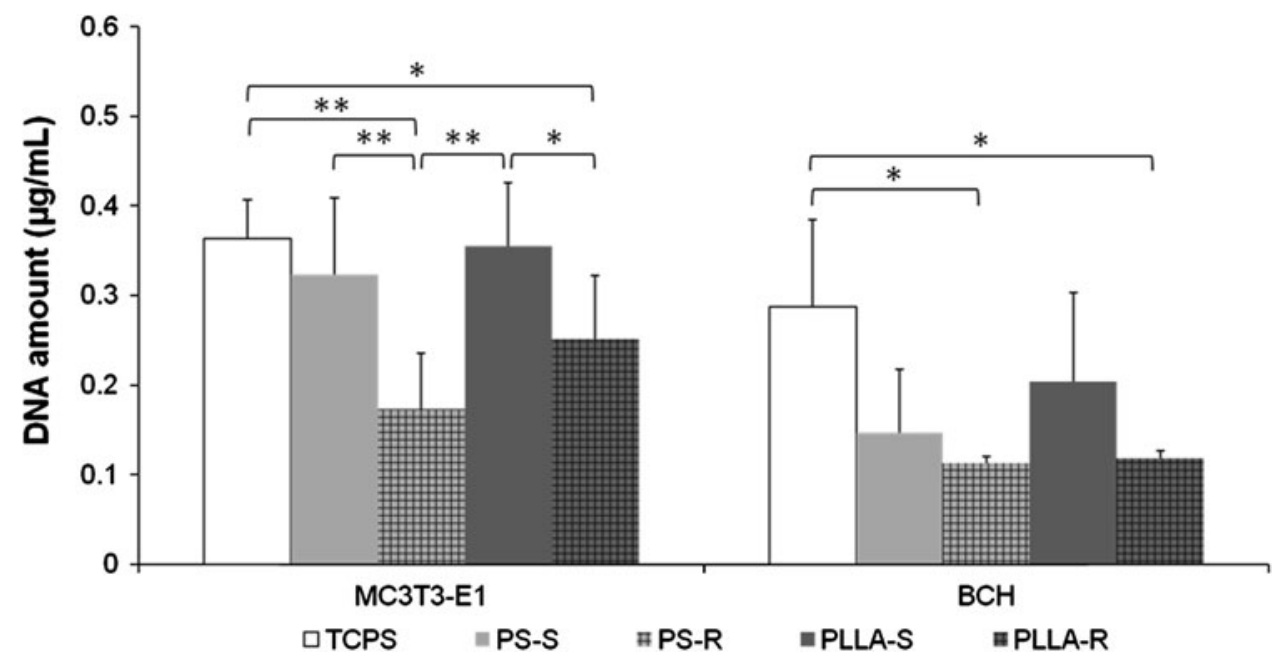

be slower on extremely hydrophobic or hydrophilic surfaces; adsorbed proteins showed altered conformation of the domains involved in cell adhesion [42], that resulting in a lack of mature focal adhesion formation, thus justifying the fact that cells do not adhere and proliferate so well on such surfaces. For superhydrophobic surfaces one should also consider the scenario in which protein adsorption and cell attachment may be prevented. The underlying mechanism could be that there is a significant fraction of the surface area that does not come into contact with the cell culture medium. The previous mentioned Cassie-Baxter hypothesis limits the mass transfer of protein to the surface and may reduce the amount of cell adhesion sites.

After initial cell adhesion, cells alter their cell membrane and morphology in order to stabilize their interaction with the substrate. The morphology of MC3T3-E1 and $\mathrm{BCH}$ cells onto smooth and rough surfaces was analyzed by SEM after 1, 3 and 7 days of culture (Fig. 10). serum proteins $[28,40,51]$. This mechanism was found to 


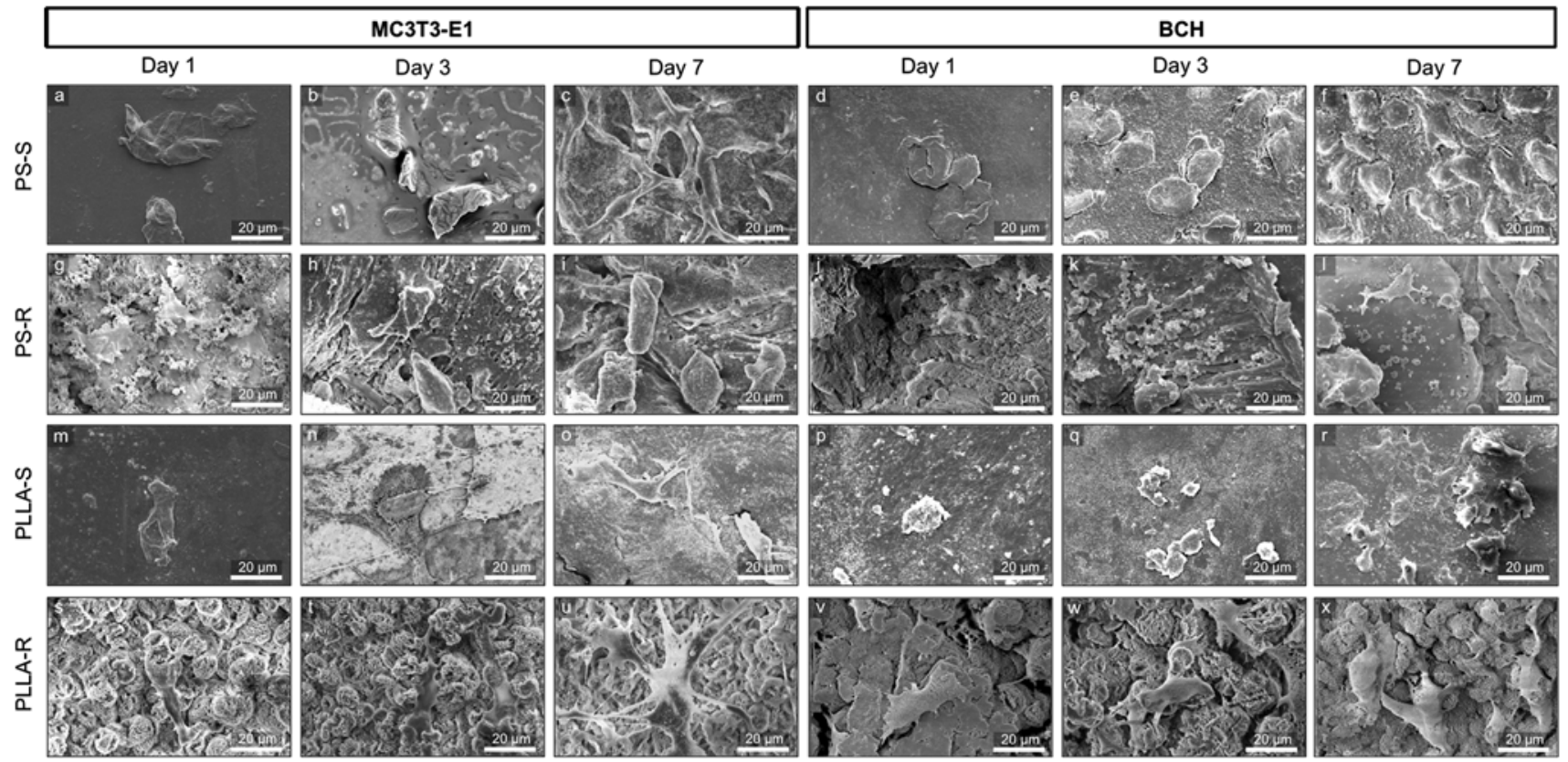

Fig. 10 SEM micrographs showing the morphology of MC3T3-E1 and BCH cells on the PS (a-l) and PLLA surfaces (m-x) after 1, 3 and 7 days in culture. Cell density: $1 \times 10^{4}$ cells $/ 300 \mu \mathrm{L}$. A representative picture for each condition is shown

Different substrate topographies may promote changes in cell adhesion, cell orientation and cell shape. On rough surfaces, focal adhesions are located at cell edges, where the contact with the substrate takes place, whereas on smooth surfaces cells tend to generate more homogeneous distribution of focal adhesions [52, 53].

MC3T3-E1 cells on PS-S and PS-R surfaces on day 1 preserved a rounded morphology, which in time changed to a more elongated and flattened shape after 3 and 7 days. Regarding the cell-material interaction on PS-R and the cell morphology we found that cells located on the surface showed an elongated morphology with high cell-cell interactions but with a low cell-material attachment. In contrast, BCH cells kept their round phenotype on PS-S surfaces during 7 days of culture period. But, on PS-R these cells only adhered to the asperities of these surfaces, where we observed a mixture of rounded and spread morphologies.

On PLLA-S surfaces, MC3T3-E1 cells exhibited a spindle shape morphology, whereas cells preferred to maintain a more flattened shape on rough surfaces. The morphology of the $\mathrm{BCH}$ cells was sustained for 3 days in culture on PLLA-S surfaces, but after 7 days in culture cells displayed a spread morphology. On PLLA-R surfaces, both types of cells were well spread and connected mainly to some points of asperities at the surfaces for the whole culture time. Probably modulated by the nano roughness of papillae-like structures of the PLLA-R substrate $\mathrm{BCH}$ cells adopted a characteristic stellate-like spread morphology. Consistent with a Cassie-Baxter scenario, this behavior could be a consequence of the non-complete wetting of the surface, due to the existence of air entrapped in micro and nano-cavities [26]. Also for PS, it could be observed that $\mathrm{BCH}$ cells exhibit a more rounded morphology on PS-S samples and that attach poorly on PS-R substrates.

The round shape of chondrocytes is an indicator of phenotype retention. The loss of cartilage phenotype of chondrocytes in culture is usually associated with changes in cell morphology, from a rounded to a spread one [54], as shown preferentially in PLLA-R or PS-R surfaces.

\section{Conclusions}

We were able to generate bioinspired superhydrophobic rough surfaces of PS and PLLA with different micro/nanotopographies by using a simple phase-separation method in a reproducible manner. PS- $R$ surfaces exhibited randomly distributed structures while PLLA-R surfaces showed individual well defined papilla-like structures with a rough texture. Results showed that similar amounts of BSA protein were adsorbed on PS or PLLA surfaces with comparable wettability. Protein adsorption was found to be lower on textured than on smooth surfaces. The cell viability, adhesion and proliferation showed that the roughness induced by phase separation reduced the affinity of MC3T3-E1 cell line and primary BCH cells. Nevertheless, cells were still metabolically active and able to adhere and survive on rough superhydrophobic surfaces. Proliferation was generally inhibited on PS-R and PLLA-R. Both 
primary chondrocytes and MC3T3-E1 cells showed similar behavior when in contact with the surfaces, although the latter seemed to be less affected.

Our results highlights the low influence of both polymer chemistry and topography of the studied superhydrophobic surfaces on cell behavior and show the influence of wettability as the main responsible factor to explain the different cell behavior on smooth and rough surfaces.

Open Access This article is distributed under the terms of the Creative Commons Attribution License which permits any use, distribution, and reproduction in any medium, provided the original author(s) and the source are credited.

\section{References}

1. Gallagher WM, Lynch I, Allen LT, Miller I, Penney SC, O'Connor DP, Pennington S, Keenan AK, Dawson KA (2006) Biomaterials 27(35):5871-5882

2. Boyan BD, Hummert TW, Dean DD, Schwartz Z (1996) Biomaterials 17(2):137-146

3. Stevens MM, George JH (2005) Science 310(5751):1135-1138

4. Chen H, Yuan L, Song W, Wu Z, Li D (2008) Prog Polym Sci 33(11):1059-1087

5. Alves NM, Pashkuleva I, Reis RL, Mano JF (2010) Small 6(20):2208-2220

6. Curtis A, Wilkinson C (2001) Mater Today 4(3):22-28

7. Flemming RG, Murphy CJ, Abrams GA, Goodman SL, Nealey PF (1999) Biomaterials 20(6):573-588

8. Bettinger CJ, Langer R, Borenstein JT (2009) Angew Chem Int Ed 48(30):5406-5415

9. Carman ML, Estes TG, Feinberg AW, Schumacher JF, Wilkerson W, Wilson LH, Callow ME, Callow JA, Brennan AB (2006) Biofouling 22(1):11-21

10. Shirtcliffe NJ, McHale G, Newton MI, Chabrol G, Perry CC (2004) Adv Mater 16(21):1929-1932

11. Ma M, Hill RM (2006) Curr Opin Colloid Interface Sci 11(4):193-202

12. Roach P, Shirtcliffe NJ, Newton MI (2008) Soft Matter 4(2):224-240

13. Zhang X, Shi F, Niu J, Jiang Y, Wang Z (2008) J Mater Chem 18(6):621-633

14. Yao X, Song Y, Jiang L (2011) Adv Mater 23(6):719-734

15. Lima AC, Song W, Blanco-Fernandez B, Alvarez-Lorenzo C, Mano JF (2011) Pharm Res 28(6):1294-1305

16. Luz GM, Leite ÁJ, Neto AI, Song W, Mano JF (2011) Mater Lett 65(2):296-299

17. Oliveira MB, Song W, Martin L, Oliveira SM, Caridade SG, Alonso M, Rodriguez-Cabello JC, Mano JF (2011) Soft Matter 7(14):6426-6434

18. Song W, Lima AC, Mano JF (2010) Soft Matter 6(23):5868-5871

19. Oliveira NM, Neto AI, Song W, Mano JF (2010) Appl Phys Express 3(8):085205

20. Neto AI, Custodio CA, Song W, Mano JF (2011) Soft Matter 7(9):4147-4151
21. Langer R, Tirrell DA (2004) Nature 428(6982):487-492

22. Hou X, Wang X, Zhu Q, Bao J, Mao C, Jiang L, Shen J (2010) Colloids Surf B 80(2):247-250

23. Oliveira SM, Song W, Alves NM, Mano JF (2011) Soft Matter 7(19):8932-8941

24. Shi J, Alves NM, Mano JF (2008) Bioinspir Biomim 3(3):034003

25. Song W, Veiga DD, Custódio CA, Mano JF (2009) Adv Mater 21(18): 1830-1834

26. Alves NM, Shi J, Oramas E, Santos JL, Tomás H, Mano JF (2009) J Biomed Mater Res Part A 91A(2):480-488

27. Sun T, Tan H, Han D, Fu Q, Jiang L (2005) Small 1(10):959-963

28. Ishizaki T, Saito N, Takai O (2010) Langmuir 26(11):8147-8154

29. Khor HL, Kuan Y, Kukula H, Tamada K, Knoll W, Moeller M, Hutmacher DW (2007) Biomacromolecules 8(5):1530-1540

30. Bergsma JE, de Bruijn WC, Rozema FR, Bos RRM, Boering G (1995) Biomaterials 16(1):25-31

31. Hollinger JO, Leong K (1996) Biomaterials 17(2):187-194

32. Hu J, Sun X, Ma H, Xie C, Chen YE, Ma PX (2010) Biomaterials 31(31):7971-7977

33. Ghosh S, Viana JC, Reis RL, Mano JF (2008) Mater Sci Eng A 490(1-2):81-89

34. Wei ZJ, Liu WL, Tian D, Xiao CL, Wang XQ (2010) Appl Surf Sci 256(12):3972-3976

35. Sun T, Feng L, Gao X, Jiang L (2005) Acc Chem Res 38(8):644-652

36. Feng XJ, Jiang L (2006) Adv Mater 18(23):3063-3078

37. Wilson CJ, Clegg RE, Leavesley DI, Pearcy MJ (2005) Tissue Eng 11(1-2):1-18

38. Elbert DL, Hubbell JA (1996) Annu Rev Mater Sci 26(1):294-365

39. Scopelliti PE, Borgonovo A, Indrieri M, Giorgetti L, Bongiorno G, Carbone R, Podestà A, Milani P (2010) PLoS One 5(7):e11862

40. Martínez EC, Hernández JCR, Machado M, Mano JF, Ribelles JLG, Pradas MM, Sánchez MS (2008) Tissue Eng Part A 14(10):1751-1762

41. Pegueroles M, Aparicio C, Bosio M, Engel E, Gil FJ, Planell JA, Altankov G (2010) Acta Biomater 6(1):291-301

42. Ballester-Beltran J, Rico P, Moratal D, Song W, Mano JF, Salmeron-Sanchez M (2011) Soft Matter 7(22):10803-10811

43. Shiu JY, Chen PL (2007) Adv Funct Mater 17(15):2680-2686

44. Koc Y, de Mello AJ, McHale G, Newton MI, Roach P, Shirtcliffe NJ (2008) Lab Chip 8(4):582-586

45. Cassie ABD, Baxter S (1944) Trans Faraday Soc 40:546-551

46. Luo S-C, Liour SS, Yu H-h (2010) Chem Commun 46(26):4731-4733

47. Wang H, Kwok DTK, Wang W, Wu Z, Tong L, Zhang Y, Chu PK (2010) Biomaterials 31(3):413-419

48. Bauer S, Park J, Mark Kvd, Schmuki P (2008) Acta Biomater 4(5): $1576-1582$

49. Shiu J-Y, Kuo C-W, Whang W-T, Chen P (2010) Lab Chip 10(5):556-558

50. Anselme K (2000) Biomaterials 21(7):667-681

51. Arima Y, Iwata H (2007) Biomaterials 28(20):3074-3082

52. Curtis A, Wilkinson C (1997) Biomaterials 18(24):1573-1583

53. Anselme K, Bigerelle M, Noel B, Dufresne E, Judas D, Iost A, Hardouin P (2000) J Biomed Mater Res 49(2):155-166

54. Von Der Mark K, Gauss V, Von Der Mark H, Muller P (1977) Nature 267(5611):531-532 